http://dx.doi.org/10.35381/r.k.v5i1.719

\title{
Provocaciones: Una experiencia que rescata el protagonismo del niño
}

\section{Provocations: An experience that rescues the role of the child}

\author{
María-del-Carmen Crespo-Argudo \\ maria.crespo.25@est.ucacue.edu.ec \\ Universidad Católica de Cuenca, Azogues \\ Ecuador \\ https://orcid.org/0000-0003-3419-7537 \\ Darwin Gabriel Garcia-Herrera \\ dggarciah@ucacue.edu.ec \\ Universidad Católica de Cuenca, Azogues \\ Ecuador \\ https://orcid.org/0000-0001-6813-8100 \\ Sandra Elizabeth Mena-Clerque \\ sandramena@ucacue.edu.ec \\ Universidad Católica de Cuenca, Cuenca \\ Ecuador \\ https://orcid.org/0000-0002-9186-2161 \\ Juan Carlos Erazo-Álvarez \\ jcerazo@ucacue.edu.ec \\ Universidad Católica de Cuenca, Cuenca \\ Ecuador \\ https://orcid.org/0000-0001-6480-2270
}

Recibido: 22 de abril de 2020 Revisado: 05 de mayo de 2020 Aprobado: 27 de mayo de 2020 Publicado: 03 de junio de 2020 


\title{
RESUMEN
}

El objetivo de este artículo fue realizar una propuesta que permita la participación activa del niño en su aprendizaje, mediante la utilización de provocaciones. El enfoque de investigación es cualitativo, desarrollándose una relación epistémica sujeto - sujeto, entre investigadores y población de estudio, se desarrolló en dos etapas: en la primera se utilizó como instrumento la entrevista a once docentes del CEI "Alonso Torres", por medio de un grupo focal mediante video conferencia para conocer las ideas sobre el protagonismo del niño en su aprendizaje, en la segunda etapa se realizó un análisis bibliográfico. Mediante la utilización de estrategias con provocaciones como una chispa que enciende la curiosidad del estudiante, invitándolo al juego que disfraza el aprendizaje; se da especial importancia a las experiencias de los niños a través de la libertad sin opresión del adulto, este escenario activa sus redes neuronales.

Descriptores: Escuela de párvulos; aprendizaje activo; experimento educacional; innovación educacional. (Palabras tomadas del Tesauro UNESCO).

\begin{abstract}
ABTRACT
The objective of this article was to make a proposal that allows the active participation of the child in his learning, through the use of provocations. The research approach is qualitative, developing a subject-subject epistemic relationship, between researchers and the study population, which took place in two stages: in the first stage, the interview with eleven teachers from the CEI "Alonso Torres" was used as an instrument, through A focus group through video conference to learn about ideas about the role of children in their learning, in the second stage a bibliographic analysis was performed. By using provocative strategies such as a spark that ignites the student's curiosity, inviting him to the game that disguises learning; Special importance is given to children's experiences through freedom without adult oppression, this scenario activates their neural networks.
\end{abstract}

Descriptors: Nursery schools; activity learning; educational experiments; educational innovations. (Words taken from the UNESCO Thesaurus).

\section{INTRODUCCIÓN}

Hoy se manifiesta mucho interés en el bienestar y la educación infantil en todo el mundo, en países referentes en calidad de educación como en Finlandia, la parte educativa se fundamenta en la capacidad del personal docente, que está muy preparado con vastos conocimientos sobre el crecimiento y desarrollo de los infantes, 
ellos valoran la infancia y utilizan una pedagogía positiva, sensible con el niño, centrada en los intereses del niño, en su curiosidad; el juego es tan importante en la educación infantil de Finlandia que la mayor parte de la jornada está dedicada al juego libre y a la actividad física que libera el excedente energético propio del niño, lo cual facilita la concentración para mejorar el aprendizaje y las habilidades motoras, asimismo cada niño es considerado como una persona valiosa, activa, competente (Nikkola, 2020); en Finlandia el sistema educativo se adapta al estudiante (Rosas et al., 2019).

Además existe una filosofia que rescata el protagonismo del niño en la infancia, se trata de Reggio Emilia, la cual busca que los estudiantes exploren de forma creativa los espacios llamados ateliers, donde aprenden al crear y experimentar; es decir son dueños de su propio aprendizaje. A nivel mundial se ha implementado la filosofía de Reggio Emilia, el que inspiró esta metodología fue Loris Malaguzzi, bajo este enfoque se respeta y escucha al niño que es protagonista de su aprendizaje, los docentes son los atelieristas o artistas, quienes son imprescindibles, deben tener mente abierta y ser sensibles ante muchas formas de conocer el mundo (Bertran-Mongay, 2017).

No obstante, por la realidad de muchas instituciones educativas fiscales del Ecuador, no se podría implementar la pedagogía Regio Emillia, por cuanto Reggio solo existe en Reggio no se puede copiar experiencias ancladas en otros contextos, pero se puede inspirar en algunos valores fundamentales de la filosofía Reggiana como dejar las hojas de trabajo, respetar la infancia, reivindicar el juego, saber que todos los espacios son educativos, de respeto y escucha al niño (Hoyuelos, 2009). Al ser la educación un derecho constitucional:

El sistema nacional de educación tendrá como finalidad el desarrollo de capacidades y potencialidades individuales y colectivas de la población, que posibiliten el aprendizaje, y la generación y utilización de conocimientos, técnicas, saberes, artes y cultura. El sistema tendrá como centro al sujeto que aprende, y funcionará de manera flexible y dinámica, incluyente, eficaz y eficiente. El sistema nacional de educación integrará una visión intercultural acorde con la diversidad geográfica, cultural y lingüística del país, y el respeto a los derechos de las comunidades, pueblos y nacionalidades. (Constitución de la República del Ecuador, 2008, p.106). 
Es por eso que para cumplir con el derecho a la educación y con el fin de orientar a los docentes en el cumplimiento de su labor en cuanto a la organización, planificación y ejecución, el Ministerio de Educación, elabora y dispone la aplicación obligatoria del currículo de educación inicial en todas las instituciones educativas que oferten este nivel.

El Ministerio de Educacion del Ecuador, 2014), menciona que el currículo de educación inicial vigente, da importancia al entorno en el que se desenvuelve el niño, por lo que se debe crear ambientes estimulantes y positivos, para buscar un aprendizaje activo en un entorno compartido, con actividades significativas, tomando en cuenta lo que necesitan desarrollar los niños, mediante procesos que permitan potencializar su pensamiento, creatividad al explorar, experimentar, jugar y crear; de esta forma el currículo de educación inicial propone orientaciones metodológicas para el desarrollo de las destrezas con procesos innovadores, interactivos e interesantes, que respeten la individualidad, gestionando una educación integral, para lo cual recomienda el uso del juego en los rincones y la organización de experiencias de aprendizaje que son vivencias, actividades desafiantes que el docente diseña intencionalmente.

Por lo que se considera que el cumplimiento del currículo puede rescatar el papel activo de los estudiantes en el proceso de aprendizaje, en las instituciones que tienen el espacio y el equipamiento adecuado para atender a los 25 alumnos, sin embargo la mayoría de las instituciones educativas que ofertan el nivel inicial en Ecuador no están preparadas para atender a 25 o mas estudiantes en una sola aula, donde tienen que adecuarse los rincones de aprendizaje.

A partir de la experiencia como docente de Educación Inicial puedo decir que hay que considerar también que los docentes al tratar de que los niños adquieran las destrezas planteadas en el currículo de educacion nacional, erróneamente estan direccionando a los niños a realizar las actividades como si se tratara de una educación tradicionalista, robotizada, donde los estudiantes son receptores de conocimientos y no autores constructores de aprendizajes significativos; a pesar de que en algunas instituciones se ha disminuido el uso de hojas de trabajo, al no existir la libertad del niño para satisfacer 
sus intereses y necesidades con respecto a la experimentación con los materiales y formas de juegos, el docente es el protagonista que decide que hacer, dejando el juego relegado unicamente para el recreo olvidando la importancia de la infancia.

Por todo lo expuesto anteriormente, el objetivo de este artículo fue realizar una propuesta que permita la participación activa del niño en su aprendizaje, mediante la utilización de provocaciones. A través de esta propuesta se busca mejorar la calidad y la calidez de la educación, por cuanto se considera que los estudiantes tienen diferentes formas de aprender; por eso se les debe brindar un espacio adecuado para la interacción, experimentación, juego, con materiales adecuados y una mediación correcta para llegar a todos los estudiantes; asimismo en este documento se toma en cuenta, que los seres humanos dependen tanto de un componente genético, como de las experiencias con el medio para configurar su aprendizaje.

\section{Referencial teórico}

\section{Experiencas y mediacion docente}

Según Escobar (2006), en los primeros años de vida la maleabilidad del cerebro le permite que se corrija, modifique, estanque o regenere con la intervención de los estímulos ambientales, por eso se recalca en la mediación e importancia de los procesos cognitivos, así como la estimulación integral en educación inicial. Los adultos deben generar experiencias de alta calidad en la primera infancia, las mismas son base para el aprendizaje posterior (Leisman, Mualem \& Mughrabi, 2015; Kolb \& Gibb, 2011) estas pueden incluso alterar la expresión de los genes.

Pro siguiendo con lo planteado, la (Foundations of School Readiness: Early Experiences Build the Brain, 2013), indica que la arquitectura del cerebro se construye en los primeros años de vida, pero continúa hasta la adultez; inicialmente se forman los circuitos más simples, luego los más complejos basados en los primeros, la interacción entre los genes y las experiencias permiten la calidad o no de la arquitectura del cerebro, el molde básico es proporcionado por los genes pero su expresión es influida por las experiencias; la capacidad del cerebro para reorganizarse y adaptarse es mayor 
en los primeros años, pues se dan un millón de nuevas conexiones por segundo, es la época de mayor actividad cerebral, por lo que en estas edades se sientan las bases sólidas o frágiles para el aprendizaje posterior.

Cuando la configuración neurológica y somática es adecuada, el niño no tiene grandes pérdidas evolutivas en su desarrollo e incluso si se somete a periodos cortos de carencias; en el caso de niños con una constitución personal no tan favorable, un buen ambiente familiar y escolar pueden suplir algunas dificultades, por el contrario si el contexto escolar es inadecuado las familias y la constitución interna del estudiante puede suplir esta carencia, entonces mientras más sean los ámbitos en condiciones negativas hay menos posibilidades de que estos puedan ser suplidos, por lo que el desarrollo puede verse afectado gravemente (Zabalza-Beraza \& Zabalza-Cerdeiriña, 2018).

Así pues la capacidad que tiene el cerebro para cambiar su actividad en respuesta a estímulos internos o externos al reorganizar su estructura, funciones o conexiones según (Mateos-Aparicio \& Rodriguez-Moreno, 2019), se llama plasticidad cerebral; mientras que la capacidad que tienen las neuronas para modificar la fuerza y eficacia de las sinapsis a través muchos mecanismos que dependen de la actividad se llama plasticidad sináptica, que está involucrada en la memoria, el aprendizaje, desarrollo cerebral, homeostasis, entrenamiento sensorial y recuperación ante lesiones cerebrales. Sin la plasticidad cerebral no fuera viable el desarrollo del cerebro desde la infancia hasta la adultez, también sería imposible recuperarse de una lesión en el cerebro, sin embargo gracias estímulos sensoriales que generan nuevas conexiones es posible (Sierra-Benítez \& León-Pérez, 2019).

Por su parte (Zabalza-Beraza \& Zabalza-Cerdeiriña, 2018), señalan que la plasticidad cerebral es mayor en los primeros años de vida, esta capacidad se va perdiendo con la edad, pero existen otros periodos de gran plasticidad como la adolescencia, sin embargo la infancia determina las bases del desarrollo normal del cerebro, aquí se forman más fácilmente y en mayor cantidad las conexiones neuronales. 
Montessori identifica 6 periodos sensibles: la sensibilidad al orden, al lenguaje, a caminar, a los aspectos sociales de la vida, a los pequeños objetos, a aprender a través de los sentidos; estas son oportunidades para afianzar y desarrollar nuevos conocimientos y habilidades en la infancia (Britton, 2001). Entonces se debe rodear al niño de experiencias adecuadas, para contribuir positivamente en el desarrollo del cerebro. Montessori resalta el valor de los primeros años de vida, llamadolos periodos sensibles, ademas señala que el educador y el medio son solo facilitadores, ya que la educación es un desarrollo protagonizado por el niño (L'Ecuye, 2012).

Para (Marholz-Aranguiz, 2017) en las artes escénicas, protagonista es aquel que tiene el papel más importante de una obra, igualmente en el campo educativo implica un desempeño activo bajo la dirección del educador, que es el productor, o sea, quien se responsabiliza de sacar adelante la obra, ya que cuenta con la planificación adecuada, prepara el espacio, los materiales e incentiva la participación de todos los actores para un adecuado aprendizaje.

Para (Vila, 2000) es importante entender que la educación infantil tiene tres actores: la familia, la escuela, y los niños; según (López \& Guiamaro, 2017) los padres así como los profesionales de la educación ayudan al desarrollo integral del infante, en donde las interacciones y el medio desencadenan las potencialidades con las que el niño nace.

La educación es la base de la formación integral de los humanos, en los primeros años debe ser integral y continua, producto de las interacciones con el medio y las experiencias que brinda la escuela para desarrollar en el niño un mejor aprendizaje, a través de estrategias pedagógicas como el juego, las artes, entre otros (Cortés \& García, 2017).

El aprendizaje es un proceso que cambia la conducta del individuo de forma relativamente permanente, este se da desde el nacimiento y es a través del juego, por lo que se debe disponer de los espacios, de experiencias adecuadas para la edad, también es importante la interacción con el adulto como jugador - vigilante de problemas que puedan ocurrir, además se debe considerar que los niños aprenden haciendo, usando sus manos; esta conexión entre cerebro y movimiento es de gran 
importancia para Montessori, pues al observar al niño se evidencia que el desarrollo mental surge de sus movimientos, igualmente debe tener la oportunidad de aprender de sus errores y perfeccionar habilidades (Britton, 2001).

Es relevante mencionar que el papel del docente es de gran importancia, para permitir que el estudiante sea el protagonista de su aprendizaje; (Didriksson, 2017), dice que el docente es la clave de la educación; según (Parra, 2014), debe estar en capacitación constante y dominar procesos de enseñanza y aprendizaje a fin de mejorar la práctica educativa; para (Mora, 2018) el maestro es la "Joya de la Corona" debido a su importancia en la educación; así mismo (Mora, 2013) indica que los maestros son la llave de la educación en la neurociencia.

Así pues, los docentes deben ser reflexivos, además tratar de conectar lo que sienten y piensan con lo que hacen y dicen, es decir, intentar engranar el ser con el hacer, para realizar una práctica docente coherente, que no se deja llevar por los demás, ya que entiende la intención de lo que hace y sabe a quién está dando voz, por ejemplo: al usar un determinado material, el educador analiza si es importante para el niño o solo es un medio para quedar bien ante las exigencias de la familia (Trueba, 2015).

Por otra parte, el docente debe crear situaciones llenas de experiencias significativas, que lleven a los niños al conflicto cognitivo, de modo que, enfrenten lo conocido con lo desconocido, en definitiva se desata un desequilibrio en sus estructuras mentales, por lo cual, busca posibles soluciones, estimula la habilidad investigativa, curiosidad y aprendizaje (Chiriboga-Posligua, 2017).

Según (Trilla-Bernet \& Puig-Rovira, 2003), los buenos educadores consideran simultáneamente la pedagogía como la configuración del medio educativo, es decir interactúan con sus alumnos y diseñan el espacio educativo, mismo que es fundamental, pues todo sitio puede servir para enseñar y aprender, pero existen lugares diseñados exclusivamente para esta tarea llamadas aulas, estas han existido desde hace mucho tiempo para trasmitir valores, conocimientos, cultura. En secuencia con el párrafo anterior, se puede decir que si el ambiente didáctico es el adecuado, despierta tanto la sensibilidad como la capacidad imaginativa que se visibiliza en la práctica las 
producciones del alma del educando, cuando se abre a la emoción y a la belleza del mundo (Cossettini, 1946).

\section{Provocaciones}

En la misma línea de las consideraciones anteriores sobre el protagonismo del niño, nos encontramos con (Camino, 2019), quien habla de la filosofía de Reggio Emilia, esta se inicia después de la segunda guerra mundial, bajo la guía de Loris Malaguzzi, esta innovación crea y facilita las condiciones para el aprendizaje al escuchar, respetar, considerar las potencialidades individuales de los niños; hace incapie en las diferentes formas que tiene el niño de ver, interpretar y relacionarse con el mundo, a lo que Malaguzzi llamó los 100 lenguajes del niño.

En la filosofia regianna el docente observa, indaga, cuestiona, prepara oportunidades de aprendizaje y documenta las experiencias de los niños; mientras el espacio es considerado como el tercer maestro, que estimula a los niños con las provocaciones para llevarlo a realizar sus exploraciones (Camino, 2019). Para que un espacio sea considerado como tercer maestro dentro del enfoque de Reggio debe haber invitaciones para el aprendizaje que logren el interés del estudiante mediante las provocaciones que sorprenden y activan la curiosidad natural del niño llevándolo a la discusión y al aprendizaje (Robson, \& Mastrangelo, 2017).

Por tal razón se deduce que, para resaltar el protagonismo del niño en su aprendizaje, se necesita de una adecuada mediación y la utilización de provocaciones, para Turner y Wilson citados por (Robson, \& Mastrangelo, 2017), una provocación es el momento en el que el docente presenta un elemento nuevo, que ha sido elegido para incitar a los niños a investigar, estos elementos pueden ser variaciones de experiencias, nuevos materiales o preguntas, integradas por el maestro o el estudiante. Entonces las provocaciones son invitaciones o sugerencias que se pueden colocar en cualquier parte del aula, de tal forma que la presencia de estos causen asombro e incentiven a los niños a intervenir con su curiosidad innata en los materiales, que son celosamente 
seleccionados para que los estudiantes generen sus aprendizajes a través de la exploración y descubrimiento, en medio del juego, con la mediacion del adulto .

Para hacer que los niños se interesen por las experiencias que les brindan los docentes, es fundamental que estas sean provocadoras, para (Zabalza-Beraza, 2018) educación inicial en su totalidad debe ser un medio provocador y estimulante, para incitar actividad cortical es importante considerar que no todos los estímulos que rodean al niño ingresan al cerebro, es decir solo los que tienen la atención del infante, lo que es sorprendente, lo que se destaca del ambiente, lo que la emoción atraiga, la tarea de la educación es orientar la atención hacia los estímulos que provoquen impacto, que enriquezcan o generen nuevas sinapsis.

Para (Mora, 2013) la emoción es una energía y la base que sustenta los procesos de aprendizaje y memoria, sí esta energía está apagada, las personas no se darían cuenta si un elefante se encuentra a lado de ellos. La emoción se enciende con la curiosidad y abre las ventanas de la atención para crear conocimiento, pues el cerebro tiene neuronas y circuitos que se activan cuando aparece algo diferente en el entorno, no se aprende de forma abstracta, solo se lo hace si algo le motiva y despierta su curiosidad; es así que para aprender solo se necesita algo interesante y nuevo, ahí también aparece el juego, que al ser una mezcla de curiosidad y placer se convierte en un instrumento poderoso de aprendizaje, la curiosidad del niño se puede encender con algunas actividades como empezar la clase con algo provocador.

Asimismo, la educación formal no debe apagar la curiosidad innata del niño, debe alentarla por cuanto muchos científicos muy exitosos, ganadores de premios novel apelan su éxito a la curiosidad que sobrevivió en ellos (Agar, 2017). Para Mora (2011) la curiosidad es parte de la naturaleza de los humanos, ella enciende la emoción y permite a los científicos poner el talento al servicio de una idea, igual pasa con los niños que buscan lo escondido, entoces la llamamos curiosidad sagrada.

Si la curiosidad es tan importante es preciso que se estimule con las provocaciones para buscar el asombro, que lleve al niño a participar activamente en su aprendizaje al jugar y experimentar con lo que le llama la atención. En este sentido el docente es un 
provocador de asombros cuando sorprende con un misterio a los estudiantes, que buscan relaciones que puede realizar para resolver el enigma; los educadores que solo repiten, no sorprenden y los estudiantes no investigan ya que solo esperan respuestas, así podemos decir que cuando se buscan relaciones posibles se habla de educación y cuando solo se repiten es escolarización (Calvo, 2013).

Para Tomas de Aquino,el asombro es el deseo para el conocimiento, mientras que en un estudio realizado por la universidad de Phensilvania, el asombro es una emoción, un sentimiento de admiración por algo que supera a uno, exhorta la apertura y la ampliación del espíritu, una experiencia que hace parar para pensar; gracias al asombro, el niño descubre la realidad, la sorpresa es la motivación, la estimulación temprana natural, lo que lo lleva a satisfacer la curiosidad, descubriendo y experimentando el funcionamiento del entorno, acompañado de un adulto que le proporcione un entorno favorable para ello (L'Ecuye, 2012).

\section{Infancia y juego}

El siguiente aspecto trata de la importancia de la primera infancia, ya que las más importantes adquisiciones cognitivas, es decir las bases del desarrollo, se dan en niños menores de 6 años, sin embargo su valor se ve reducido a actividades únicamente de cuidado, por lo que la práctica educativa con los niños del nivel inicial, debe sustentarse a los avances tanto de la neurociencia como de la psicología, además de respetar sus necesidades y capacidades del desarrollo, para no continuar con actividades pedagógicas rutinarias, mecánicas (corte, pegue) que no provocan reflexión ni estimulación de sus capacidades cognitivas (Escobar, 2006).

No se pueden utilizar cuadernillos, libros, hojas de trabajo; para algunos docentes sin capacidad crítica reproducen en sus aulas actividades para complacer a los padres de familia que quieren lucir a sus hijos, por lo que los niños de 3 a 6 años incluso los de 1 a 2 están utilizando hojas de trabajo para aprender a leer, contar escribir, usan instrumentos que el mercado ha sacado para la estimulación precoz, convirtiendo a los niños en mercancía; según Loris Magaluzzi esto roba la infancia conduciendo a 
aprendizajes instrumentales para adiestrar a los niños reduciéndolos a animales de circo (Hoyuelos, 2010).

Lo siguiente es recordar que los estudiantes, son seres únicos e irrepetibles, que, gracias a la mediación docente, escenografía y materiales adecuados son llevados tanto al asombro, como a la curiosidad, mientras son felices con el juego; para (Tamayo-Giraldo \& Restrepo-Soto, 2017), lo lúdico está tomando mayor importancia en los ambientes educativos, permitiendo al niño conocer el entorno y desarrollar procesos mentales superiores; asimismo le permite solucionar las barreras exploratorias con la satisfacción placentera que le presta, incluso la cultura humana surge de la capacidad para jugar.

Hay que lograr que el niño estimule, potencie todas sus capacidades sin que se dé cuenta, la mejor vía es el juego y el super héroe que ayudará a ello, es el maestro; siendo un mediador que le aporta seguridad, resuelve sus incógnitas, crea conflictos cognitivos por medio de los materiales y juegos que debe preparar con antelación considerando las características de su estudiantado, anticipándose a las reacciones de los pequeños, pensando en el interés que van a causar y los aprendizajes que puede ocasionar.

Así mismo, (Edo, Blanch \& Anton, 2016), señalan que el juego es una actividad placentera, libre, voluntaria que permite explorar, descubrir, experimentar, crear, ejercitar, ayuda al desarrollo psicomotor, estimula el lenguaje, el pensamiento, la curiosidad, la creatividad; es un medio de aprendizaje que permite, resolver problemas, controlar las emociones, respetar reglas e interactuar y cooperar con los demás; por tanto estimular la actividad lúdica es igual que potenciar el desarrollo infantil, por otro laado (The Lego Foundation en apoyo de UNICEF, 2018) manifiesta que las capacidades básicas que obtienen los niños mediante el juego en la primera infancia integran lo que en años ulteriores serán los componentes más importantes de las llamadas competencias del siglo XXI. 


\section{MÉTODO}

El enfoque de investigación es cualitativo, desarrollándose una relación epistémica sujeto - sujeto, entre investigadores y población de estudio, conociéndose el objeto de estudio desde la intersubjetividad de las personas involucradas (Aldana-Zavala, 2019), además se usó una metodología bibliográfica (Mogrovejo-Gavilanes, Erazo-Álvarez, Pozo-Cabrera, \& Narváez-Zurita, 2020), este trabajo investigativo se desarrolló en dos etapas: en la primera se utilizó como instrumento la entrevista a once docentes del CEI "Alonso Torres", por medio de un grupo focal mediante video conferencia para conocer las ideas sobre el protagonismo del niño en su aprendizaje, en la segunda etapa se realizó un análisis bibliográfico, partiendo de fuentes documentales como artículos científicos, libros, ponencias entre otros, mediante el empleo del software Harzing y bases de datos científicas para la posterior construcción de una propuesta con el empleo de provocaciones.

\section{RESULTADOS Y APORTES GENERADOS}

En una encuesta realizada a docentes de educacion inicial, con el proposito de saber cuál es el protagonismo del niño en su aprendizaje se evidencia en la siguiente tabla. 


\section{Tabla 1}

Principales aportes sobre el protagonismo del niño.

\section{Unidad de Análisis}

Protagonismo del niño

\section{Respuestas}

Las actividades son direccionadas por la maestra, no nacen de los niños ya que ellos no son capaces de aprender por si solos debido a su edad

Dificultades en el proceso de enseñanza y aprendizaje

Los niños no atienden, no se concentran en la clase, quieren jugar.

Relación de los niños con los materiales.

Objetivo principal de las clases El objetivo es la adquisición de destrezas.

El juego
El niño puede jugar en el recreo, cuando el juego es una actividad de la planificación puede hacerlo en el aula.

Fuente: Elaboración propia: Entrevista a docentes.

Por experiencia personal y la de los entrevistados, al tratar que los estudiantes adquieran destrezas, se descuida el papel protagónico que debe tener el niño en su aprendizaje, se relega la actividad más importante de la infancia que es el juego únicamente para el recreo; se prioriza la disciplina y la atención en la clase, dicho de otra manera, se olvida que se trata de niños con intereses distintos, posiblemente la meta de ellos no es adquirir destrezas, es divertirse.

A partir de las entrevistas de los docentes y con la fundamentacion teorica expuesta en este articulo se desarrola la propuesta "Rescatando la Infancia con Provocaciones" como se observa en el figura 1. 


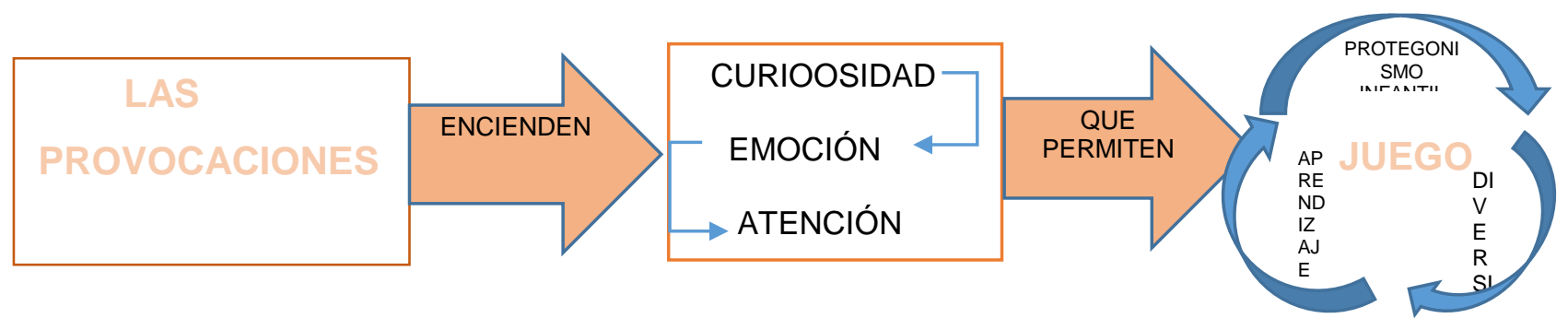

Figura 1. Rescatando a la infancia con provocaciones. Fuente: Elaboración propia

\section{Estrategias:}

\section{a. Dotar de tantas experiencias como sea posible al niño para su participación activa.}

Es decir, permitir que el niño explore, experimente en escenarios ricos creados por los docentes, aprovechando cualquier situación para llevar al niño al juego, a la reflexión y al aprendizaje.

\section{b. Usar las provocaciones para buscar la atención en los niños.}

El niño necesita del asombro ocasionado por ese algo diferente que el docente integra al entorno, en ese momento de emoción el niño está predispuesto para aprender a través del juego, la curiosidad lo llevará a descubrir y experimentar, todo gracias a la presencia del asombro que rescata el papel activo del niño en la educación.

Las provocaciones pueden ser, preguntas, situaciones, personas, pero principalmente son los materiales que buscan llamar la atención del estudiante para que simplemente juegue.

Los materiales provocadores dependen de la realidad de cada institución, así como de la situación económica; hay que considerar que los mejores materiales son los que provienen del ambiente natural piedritas, hojas secas, arena, semillas; los reciclados como las botellas, rollos de papel, recipientes de todo tamaño. 


\section{c. Juego Libre}

Las experiencias lúdicas de los niños generan aprendizajes, entonces, en vez de relegar el juego únicamente para la hora del recreo, se lo debe incluir en todo lo que le rodea al niño, en efecto al infante no le cuesta jugar, lo hace todo el tiempo, si le preguntan a un niño que es lo que más le gusta de su escuela, seguramente responderá el recreo, si le preguntan a un adulto que es lo que más le disgusta cuando dicta sus clases, seguramente responderá que los alumnos se distraen jugando; en esta propuesta el juego no es igual a distracción, es sinónimo de infancia, hay que dejar que el niño haga lo que más le gusta, que es jugar sin la dirección del adulto, el juego le proporcionará aprendizajes, es por eso que el papel del docente es generar las provocaciones más adecuadas para que el niño juegue como el quiera.

$\mathrm{Si}$ el educador que es una persona preparada, creativa busca los materiales adecuados (Romero-Ramírez, 2020), el niño disfruta del material y aprende, el maestro debe estar ahí, observando el juego, listo para responder las preguntas que se generan, preparado para actuar en caso de peligro o situaciones conflictivas, motivado para jugar cuando los niños lo inviten y analizando la relación del niño con el entorno para en la próxima ocasión perfeccionar las provocaciones.

\section{d. Considerar al desarrollo del niño como un proceso conjunto}

El desarrollo del niño no es un proceso aislado, necesita del apoyo de la comunidad, de los representantes, de la institución educativa, para asegurar que se cumplan los derechos del infante y velar por su bienestar físico y emocional.

El niño aporta su potencial genético y su auto aprendizaje mediante el juego, los docentes le proporcionan experiencias ricas y variadas con ayuda de las provocaciones, los padres de familia mantienen armonía en el hogar, además satisfacen todas las necesidades del infante, también mantienen una comunicación asertiva con la institución educativa; de esta forma el desarrollo del niño es de forma conjunta. 
Es necesario que la docente mantenga un diálogo constante con los padres del estudiante (Páez, 2018), no solo para conocer sobre sus gustos y preferencias sino además para enriquecer aún más las experiencias de los niños en el caso de hogares desfavorecidos, además es primordial que los padres conozcan el porqué del actuar docente para que no se presione al niño buscando aprendizajes para los que no está preparado, por ejemplo en el caso de los estudiantes que van a primero de básica la familia desea que la maestra le enseñe a escribir el nombre, el representante debe saber que el niño lo hará cuando esté listo y no como resultado de una escolarización precoz. Es primordial además que se realice un trabajo coordinado entre los directivos y docentes para sumar a ello la participación de los representantes y la comunidad.

\section{Elementos básicos}

Esta propuesta tiene tres elementos básicos, que todo docente debe tener en cuenta: el saber, el hacer, el respetar y el sentir.

1. Saber que todo lo que está a su alrededor influye en su desarrollo integral sea positiva o negativamente, para buscar el mayor provecho de las experiencias que el niño tiene con la realidad mediante el juego, motivado por el asombro, creando situaciones donde el niño entre en conflicto o aprovechando situaciones para la reflexión.

2. Hacer que el niño regrese a cumplir su rol más importante, el papel de niño, aprovechando al máximo la niñez, para dejarle realizar lo que más le gusta, recordando que este tiempo no volverá.

3. Respetar al niño y el contexto, trayendo hasta su medio, situaciones de acuerdo a su realidad, aprovechando los materiales del medio en el que se encuentra, rescatando el asombro por aquellas cosas que han sido olvidadas pero que aún están ahí.

4. Sentir empatía con los niños, ponerse en la situación de ellos, mirar el mundo desde su óptica, para hacer oportuna la educación, para dejar la escolarización, 
para amar la profesión docente, para tratarlos como familia, solo así se puede ofrecer una educación de calidad y calidez.

\section{¿Cómo llevar a la práctica las provocaciones?}

Para sorprender aún más al niño y robar toda su atención se pone en consideración estos elementos provocadores:

Caja de sorpresas

Es una caja de cualquier material con decoración llamativa, la caja no debe dejar ver lo que hay adentro, pero necesita un espacio por donde pueda ingresar las manos para sacar los objetos, esta contendrá elementos que agraden a los niños, pueden ser títeres, cuentos, imágenes que despertarán la curiosidad del niño; todos los días la maestra coloca intencionalmente materiales que propicien el diálogo, la reflexión, el aprendizaje o la diversión. Esta caja se puede usar en las actividades iniciales para que no sean monótonas y se escoja de la caja la actividad que se va a realizar.

1. Dado mágico. Es un dado realizado con una caja de cartón u otro material, en cada lado estará pegada una fotografía donde consten los ambientes en los que queremos jugar, se utiliza para determinar el ambiente donde se va a jugar.

2. Imágenes provocadoras. Son cuadrados de cartulina blanca con fotos de actividades que le gusta al grupo de niños, la docente que conoce a los estudiantes selecciona las fotografías, por ejemplo, de niños bailando, niños cantando, jugando, escuchando un cuento, observando títeres, etc.; estas imágenes deben ser colocadas en la caja de sorteo. Son muy útiles en las actividades finales y determinan las actividades que se van a realizar para la despedida.

3. Caja de sorteo. Es una caja en la que se coloca las imágenes provocadoras para los sorteos.

4. Espacio de encuentro. Es importante tener en el aula un espacio para el encuentro de todos, debe ser agradable alejado de la escolarización es decir sin sillas y mesas donde se encuentren los estudiantes como soldados, se puede 
usar una alfombra, estera, cojines elaborados por las familias para estar cómodos; este es el único lugar donde la maestra dirige una actividad, el tiempo en este espacio no debe exceder los 30 minutos, se usa para actividades iniciales y finales, el resto de tiempo es ocupado por el juego libre con los materiales diseñados con anterioridad.

5. Caja con provocaciones. Es una caja de cartón, madera, metal, o plástico resistente, espacioso y fácil de transportar donde se colocan los materiales provocativos que invitan a explorar, experimentar y jugar.

En las instituciones que poseen una sola aula de inicial, la docente coloca las provocaciones en el aula, para convertir el espacio en cualquier ambiente, el juego empieza cuando se lanza en el espacio de encuentro el dado mágico que indica el ambiente en el que se transformará el aula con los materiales provocadores.

Con la caja de provocaciones se puede trasladar a cualquier lugar los ambientes de aprendizaje, de esta forma un patio, una cancha, un parque, el vecindario puede ser el ambiente deseado para el juego, creación e investigación.

En las instituciones en las que se cuenta con un aula para cada ambiente, se debe colocar las provocaciones anticipadamente en un lugar visible del aula, para cuando pasen por ese ambiente los estudiantes hagan uso de estos elementos como creyeren conveniente, de esta forma los infantes pueden jugar, crear y desarrollar libremente sin presiones las destrezas.

En el día se puede realizar dos rotes, es decir se trabaja con dos ambientes, para darle tiempo al niño a explorar, experimentar y jugar. A continuación se ejemplifica las provocaciones para la destreza: utilizar la pinza digital para coger lápices, marcadores, pinceles y diversos tipos de materiales (Ministerio de Educación del Ecuador, 2014).

Botellas de plástico vacías, semillas dispersas en cestos grandes, botellas con frutos, los niños en algún momento al ver algunas botellas que contienen semillas, les va a provocar utilizar las botellas vacías para colocar las semillas dispersas, como son muy pequeñas, la única opción será usar la pinza digital para introducirlas en las botellas. 
Pinzas de ropa agarradas en cuerdas, pinzas de cejas en un cesto con lentejuelas, son muy buenas provocaciones para invitar al niño usar la pinza digital.

Cajas con agujeros pequeñas, donde pueden ingresar únicamente dos dedos; estas deben contener materiales pequeños llamativos que inviten al niño a manipularlos, se puede colocar cerca hojas de papel, goma. La curiosidad innata de los niños provoca que quieran sacar los objetos de los agujeros, pero como estos son estrechos, una opción es usar sus dedos índice y pulgar para sacar los materiales y quizá crear obras de arte con la goma y las hojas.

Asimismo, se puede usar plástico de burbujas (film alveolar) para envoltura de material delicado, ¿quién no se ha divertido al explotar estas burbujas de aire?, al niño seguramente le encanta y se puede ayudar de la pinza digital para jugar con este material.

Si a los niños no les llama la atención los materiales anteriores, al ver una manilla o un collar colocados en un recipiente lleno de cuentas junto a lana cortada, el niño a lo mejor quiera convertirse en un artesano que hace creaciones maravillosas.

Después de que los niños hayan ejercitado su pinza digital durante varias ocasiones con materiales provocadores como los anteriores, el docente debe colocar provocaciones como pinceles, marcadores, pinturas, crayones, cartulinas, hojas, etcétera.

El docente no le dice como trabajar con el material, el niño por su cuenta investiga, experimenta y juega con el material, el docente observa, da seguridad e interviene en caso de situaciones de peligro, para resolver interrogantes, para crear conflictos cognitivos, para invitar a la reflexión.

Las provocaciones no son solo los materiales adecuados, es como el docente hace las preguntas adecuadas en el momento adecuado; es importante que el docente responda las preguntas de los estudiantes, pero también haga preguntas como estas ¿qué crees tú que está pasando? ¿Cómo lo resolverías tú? ¿Por qué crees que ocurre esto? ¿Cuál escogerías tú? ¿De qué manera crees que funcione?, es decir preguntas que motiven al niño a pensar, reflexionar, y encontrar posibles soluciones. 
Para trabajar dentro de una aula, las provocaciones se colocan en un lugar visible para todos, debe haber suficiente material para los estudiantes; se debe prever con anticipación las provocaciones de acuerdo a lo que se desea que conozcan los estudiantes.

Se considera, que el mayor aporte que tiene este trabajo es, que contribuye con una propuesta que se aplica a cualquier contexto escolar y permite además cumplir con el currículo de educación inicial que promueve la participación activa del niño en su aprendizaje.

La educación es un proceso conjunto que requiere el esfuerzo particularmente del docente, que es considerado como la clave que posibilita el éxito de la educación.

Se debe dejar que el niño viva su infancia, pues es una etapa que ningún ser humano puede volver a vivir; además es la gestora de la arquitectura del cerebro humano, por lo que se le debe dar la importancia que merece.

Las provocaciones rescatan el protagonismo del niño en su aprendizaje, pues permiten que el niño explore, experimente, juegue sin la opresión del docente que se convierte en un mediador que le brinda protección, seguridad y las experiencias.

Esta es una invitación a investigadores, de manera especial a las personas que trabajan en el campo educativo, para enriquecer esta propuesta llevándola a la práctica en diferentes contextos.

\section{FINANCIAMIENTO}

No monetario.

\section{AGRADECIMIENTO}

Al personal directivo y docente del CEI Alonso Torres por apoyar la investigación. 


\section{REFERENCIAS CONSULTADAS}

Aldana-Zavala, J. J. (2019). La competencia epistemológica en el investigador social universitario venezolano. [Epistemological competence in the Venezuelan university social researcher]. Praxis, 15(1), 103-115. https://doi.org/10.21676/23897856.3091

Agar, J. (2017). Wilkins-Bernal-Medawar lecture The curious history of curiosity-driven research. [Conferencia de Wilkins-Bernal-Medawar La curiosa historia de la investigación impulsada por la curiosidad]. Notes and records of the Royal Society of London, 71(4), 409-429. https://doi.org/10.1098/rsnr.2017.0034

Bertran-Mongay, N. (2017). Laboratorio de experiencias: el atelier en el aula. Recuperado de https://n9.cl/tyb6w

Britton, L. (2001). Jugar y Aprender - El Metodo Montessori. [Play and Learn - The Montessori Method]. Paidós Educación.

Calvo, C. (2013). Propensión a aprender y desescolarización de la escuela. [Propensity to Learn and the Unschooling of School]. Logos: Revista de Lingüística, Filosofía y Literatura. 24(1), 66-74. https://doi.org/10.15443/RL2406

Camino, k. (2019). Reggio Emilia: una filosofia sensible al niño. [Reggio Emilia: a childsensitive philosophy]. Revista Educativa para Docentes Parvularias. Recuperado de https://n9.cl/0y89

Chiriboga-Posligua, M. F. (2017). Los conflictos cognitivos como base fundamental para el desarrollo de las habilidades investigativas en educación infantil. [Cognitive conflicts as a fundamental basis for the development of investigative skills in early childhood education].Memorias del tercer Congreso Internacional de Ciencias Pedagógicas : Por una educación inclusiva: con todos y para el bien de todos / coord. por Manuel Roberto Tolozano Benítez, Rosalía Arteaga Serrano, 2017, ISBN 978-9942-17-027-9, págs. 535-543. Recuperado de https://n9.cl/yw0l

Cortés, A, \& García, G. (2017). Estrategias pedagogicas que favorecen el aprendizaje de niñas y niños de 0 a 6 años de edad en Villavicencio-Colombia. [Teaching strategies to enhance learning in children from 0 to 6 years at Villavicencio Colombia]. Revista Interamericana De Investigación, Educación y Pedagogía. 10(1), 125-143. Recuperado de https://n9.cl/g7toe

Cossettini, O. (1946). La estética en la escuela. [Aesthetics at school]. Recuperado de https://n9.cl/r5pyg 
Constitución de la República del Ecuador (2008). Título II. Derechos. Sección Quinta. Educación. [Title II. Rights. Fifth Section. Education]. Recuperado de https://n9.cl/sia

Didriksson, A. (2017). Pasi Sahlberg. El cambio educativo en Finlandia ¿Qué puede aprender el mundo? [Pasi Sahlberg. Educational change in Finland What can the world learn?]. Perfiles educativos, 39(157), 222-227.

Edo, M, Blanch, S, \& Anton, M. (2016). El juego en la primera infancia. [Play in early childhood]. Recuperado de https://n9.cl/gqxi

Escobar, F. (2006). Importancia de la educación inicial a partir de la mediacion de los procesos cognitivos para el desarrollo humano integral. [Importance of initial education from the mediation of cognitive processes for integral human development]. Laurus, 12(21), 169-194. Recuperado de https://n9.cl/a1om

Foundations of School Readiness: Early Experiences Build the Brain (2013). El desarrollo del cerebro y su relación con la preparación para la escuela. [Brain development and its relationship to school readiness]. Recuperado de https://n9.cl/0qx5

Hoyuelos, A. (2009). Ir y descender a y desde Reggio Emilia. [To go and descend to and from Reggio Emilia]. CEE Participación Educativa. 12, 171-181. Recuperado de https://n9.cl/dt0x8

Hoyuelos, A. (2010). La identidad de la educación infantil. [The identity of early childhood education]. Educação, 35(1), 15-23. Recuperado de https://n9.cl/3jg8

Kolb, B., \& Gibb, R. (2011). Brain plasticity and behaviour in the developing brain. [Brain plasticity and behavior in the developing brain]. Journal of the Canadian Academy of Child and Adolescent Psychiatry = Journal de l'Academie canadienne de psychiatrie de l'enfant et de l'adolescent, 20(4), 265-276.

L'Ecuye, C. (2012). Educar en el asombro. [Educate in awe]. Barcelona: Plataforma editorial.

Leisman, G, Mualem, R, \& Mughrabi, S. (2015). The neurological development of the child with the educational enrichment in mind. [El desarrollo neurológico del niño con el enriquecimiento educativo en mente]. Psicología Educativa, 21(2), 79-96. https://doi.org/10.1016/j.pse.2015.08.006 
López, G., \& Guiamaro, Y. (2017). El rol de la familia en los procesos de educación y desarrollo humano de los niños y niñas. Ixaya. Revista Universitaria de Desarrollo Social, o(10), 31-55. Recuperado de https://n9.cl/ps42u

Mateos-Aparicio, P, \& Rodriguez-Moreno. A. (2019). The Impact of Studying Brain Plasticity. [The Impact of Studying Brain Plasticity]. Frontiers in cellular neuroscience, 13, 66. https://doi.org/10.3389/fncel.2019.00066

Marholz-Aranguiz, G. M. (2017). Retornado a las ideas fundantes de la educación para la primera infancia: el protagonismo de los niños y niñas en el siglo XXI, una tarea compleja. [Returned to the funding ideas of education for the first infancy: the boys and girls protagonism in the XXI century, a complex task]. Revista Infancia, Educación y Aprendizaje, 3 (1), 205-216. https://doi.org/10.22370/ieya.2017.3.1.1193

Ministerio de Educacion del Ecuador (2014). Currículo de Educacion Inicial. [Currículo de Educacion Inicial]. Recuperado de https://n9.cl/47zr

Mogrovejo-Gavilanes, A., Erazo-Álvarez, J., Pozo-Cabrera, E., \& Narváez-Zurita, C. (2020). Aplicación del Principio de proporcionalidad en la Jurisprudencia de la Corte Constitucional del Ecuador. [Application of the Principle of proportionality in the Jurisprudence of the Constitutional Court of Ecuador]. IUSTITIA SOCIALIS, 5(8), 91-116. http://dx.doi.org/10.35381/racji.v5i8.563

Mora, F. (2011). El científico curioso: la ciencia del cerebro en el día a día. [The curious scientist: the science of the brain in everyday life]. Recuperado de https://n9.cl/j7b1

Mora, F. (2013). Neuroeducacion: solo se puede aprender aquello que se ama. [Neuroeducation: you can only learn what you love]. Madrid. Alianza Editorial.

Mora, F. [Aprendemos juntos]. (5 de diciembre de 2018). El maestro es la joya de la corona de un país. [The teacher is the jewel in the crown of a country]. [Archivo de video]. Recuperado de https://n9.cl/bc3wq

Nikkola, V. (2020). Educación y atención a la infancia en Finlandia. [Education and care for children in Finland]. Educació Social. Revista d'Intervenció Socioeducativa, 74, 73-88. 
Páez, A. (2018). Docentes y padres en el proceso de aprendizaje de los estudiantes. [Teachers and parents in the student learning process]. EPISTEME KOINONIA, 1(2), 18-34. http://dx.doi.org/10.35381/e.k.v1i2.509

Parra F., K. N. (2014). El docente y el uso de la mediación en los procesos de enseñanza y aprendizaje. [The teacher in the classroom and the use of mediation in the processes of teaching and learning]. Revista de Investigación, 38 (83), 155180. Recuperado de https://n9.cl/podif

Romero-Ramírez, M. (2020). Vocación docente como respuesta esperanzadora en contextos de vínculos humanos frágiles. [Teaching vocation as a hopeful response in contexts of fragile human ties]. EPISTEME KOINONIA, 3(5), 27-50. http://dx.doi.org/10.35381/e.k.v3i5.527

Robson, K, \& Mastrangelo, S. (2017). Children's Views of the Learning Environment: A Study Exploring the Reggio Emilia Principle of the Environment as the Third Teacher. [Las opiniones de los niños sobre el entorno de aprendizaje: un estudio que explora el principio de Reggio Emilia del entorno como tercer maestro]. Journal of Childhood Studies. 42(4), 1-16.

Rosas, R, Staig, J, Lazcano, G, Palacios, R, Espinoza, V, Aro, M, \& Imbernón, C. (2019) ¿Qué Podemos Aprender de los Sistemas Educativos de Chile, España y Finlandia en el Marco de la Declaración de Salamanca? [What Can We Learn from the Educational Systems of Chile, Spain and Finland in the Framework of the Salamanca Declaration?]. Revista Latinoamericana de Educación Inclusiva. 13(2), 57-74. Recuperado de https://n9.cl/0i2l

Sierra-Benítez, E, \& León-Pérez, M. (2019). Plasticidad cerebral, una realidad neuronal. [Brain Plasticity: a neuronal reality]. Revista de Ciencias Médicas de Pinar del Río, 23(4), 599-609.

Tamayo-Giraldo, A, \& Restrepo-Soto, J. (2017). El juego como mediación pedagógica en la comunidad de una institución de protección, una experiencia llena de sentidos. [Play as a pedagogical mediation in the community of a protection institution, an experience full of senses]. Revista Latinoamericana de Estudios Educativos (Colombia), 13(1), 105-128. Recuperado de https://n9.cl/t104f

Trilla-Bernet, J, \& Puig-Rovira, J. (2003). El aula como espacio educativo. [The classroom as an educational space]. Cuadernos de pedagogía, 325, 52-55.

Trueba, B. (2015). Espacios en armonía: Propuestas de actuación en ambientes para la infancia. [Spaces in harmony: Proposals for action in environments for children]. Barcelona: Octaedro. 
The Lego Foundation en apoyo de UNICEF (2018). Aprendizaje a través del juego. Reforzar el aprendizaje a través del juego en los programas de educación en la primera infancia. [Learning through games. Reinforce learning through play in early childhood education programs]. Recuperado de https://n9.cl/8r4n

Vila, I. (2000). Aproximación a la educación infantil: características e implicaciones educativas. [Approach to early childhood education: educational characteristics and implications]. Revista Iberoamericana de Educación. № 22. p. 41-60. Recuperado de https://n9.cl/yor6

Zabalza-Beraza, M, \& Zabalza-Cerdeiriña, M. (2018). Neurociencias y Formación De Profesores Para La Educación Infantil. [Neurosciences and teacher training for early childhood education]. RELAdEl. Revista Latinoamericana De Educación Infantil, 7(1), 78-85.

Zabalza-Beraza, M. (2018). La educación infantil como tarea compartida. [Early childhood education as a shared task]. RELAdEl. Revista Latinoamericana De Educación Infantil, 4(2), 13-15. 